\title{
Estudo do processo de comunicação de alunos com paralisia cerebral em ambientes digitais de aprendizagem
}

\author{
Tatiana Lima dos Santos da Cunha \\ Universidade Federal do Rio Grande do Sul (UFRGS) \\ Programa de Pós-Graduação em Informática na Educação \\ Orientador: Prof ${ }^{\mathrm{a}} \mathrm{Dr}^{\mathrm{a}}$ Lucila Maria Costi Santarosa (UFRGS) \\ Co-Orientador: $\operatorname{Prof}^{\mathrm{o}} \mathrm{Dr}^{\mathrm{o}} \mathrm{J}$ sé Valdeni de Lima (UFRGS)
}

\begin{abstract}
This study aimed to identify possible contributions of using Digital Environments, the students communication process with cerebral palsy. The subjects used some Digital Environments, including the Eduquito and a social network. From the mediation and virtual contact with other children, the dimensions were observed reading and writing, oral language, and social development. The results showed that children began to virtually interact with other children and have appropriated new concepts and new technologies. There was an evolution in the written language as well as a decrease in production misspelled during the search time.
\end{abstract}

Resumo. O presente trabalho se propôs a identificar as possíveis contribuições da utilização de Ambientes Digitais, no processo de comunicação de alunos com paralisia cerebral. Os sujeitos utilizaram os ambientes Eduquito e uma rede social. A partir da mediação e do contato virtual com outras crianças, foram observadas as dimensões da leitura e escrita, da linguagem oral, e seu desenvolvimento social. Os resultados mostraram que as crianças passaram a interagir virtualmente com outras crianças e se apropriaram de novos conceitos e novas tecnologías. Observou-se uma evolução na linguagem escrita, bem como uma diminuição na produção de erros ortográficos durante o tempo de pesquisa.

\section{Introdução}

O trabalho proposto surgiu de uma inquietação sobre o benefício das novas tecnologias para a comunicação de pessoas com deficiência. Estudos ${ }^{1}$ apontam para o benefício que o uso dos recursos da informática traz aos alunos com deficiência. O acesso aos recursos oferecidos pela sociedade, pela escola, pela tecnologia e pela informática influencia determinantemente nos processos de aprendizagem e desenvolvimento do aluno.

Atualmente, vivemos em uma época em que a tecnologia tem contribuído para facilitar o desenvolvimento do ser humano em diversos setores de sua vida, inclusive na sua educação. Em função das limitações motoras e/ou comunicação oral, alunos com deficiência são muitas vezes excluídos do convívio social, bem como da sua introdução nas classes regulares de ensino. Visando melhorar a qualidade de vida dessas pessoas, tornando-as mais ativas e participativas da sociedade em geral, estão sendo utilizados novos recursos tecnológicos, para auxiliar no processo de inclusão escolar e

\footnotetext{
${ }^{1}$ Rabello (2007); Beck (2007); Galvão Filho e Damasceno (2008); Rocha e Deliberato (2012).
} 


\section{sociodigital.}

Oportunizar o acesso ao mundo digital a todos os indivíduos é premissa básica para uma sociedade que preconiza a participação ampla de todos os seus cidadãos, o respeito às diferenças e a igualdade de oportunidades. Os recursos tecnológicos podem possibilitar uma mediação entre a criança e o aprendizado. Para a criança com Paralisia Cerebral (PC), esse recurso ainda favorece a comunicação por meio das interações sociais. Além disso, é importante destacar o papel assumido pela interação no desenvolvimento dos indivíduos. Sob esse ponto de vista, apresenta-se como fundamental, o aporte da teoria sociointeracionista de Vygotsky, em que são estudadas as formas como os seres humanos desenvolvem os mecanismos intencionais, as ações conscientemente controladas que os diferenciam dos demais seres vivos. Vygotsky (2007) aponta o papel fundamental da interação entre indivíduos com diferentes níveis de desenvolvimento.

A comunicação é uma necessidade que está presente na vida do ser humano. Ela é responsável pela troca de informações entre as pessoas e pela interação. $\mathrm{O}$ homem aperfeiçoou sua comunicação e iniciou a utilização de meios para facilitar esse processo, bem como a sua capacidade de relacionamento. Hoje em dia, a comunicação escrita tem sido a forma de comunicação mais utilizada nos meios digitais. A leitura e a escrita são muito importantes para que as pessoas exerçam seus direitos, possam trabalhar e participar da sociedade com cidadania, informar-se e aprender ao longo de toda a vida.

Novas tecnologias foram criadas a partir das necessidades que foram surgindo ao longo dos anos e têm possibilitado acesso à dispositivos computacionais, maior autonomia e independência em atividades acadêmicas, profissionais, domésticas e de entretenimento a pessoas com deficiências - algo pouco provável há poucos anos. Dessa forma, assume-se que a tecnologia oferece recursos que possibilitam o desenvolvimento da criança com PC. Em seus relatos, Vygotsky (2011) afirma que as leis que fundamentam o desenvolvimento são as mesmas para as crianças normais e para as crianças com deficiências, e que esses indivíduos devem usar seus sentidos "sadios" para compreenderem o mundo, ou seja, devem utilizar suas capacidades para compensar seus sentidos comprometidos.

O crescente desenvolvimento das tecnologias da informação vem contribuindo para a democratização da utilização dos espaços virtuais. Mas será que as novas tecnologias são capazes de melhorar a comunicação dos indivíduos com deficiência?

Alunos com deficiências, especialmente com PC, podem beneficiar-se no seu desenvolvimento global, desafiando os prognósticos clínicos e, principalmente, os educacionais. Com a evolução e o uso da tecnologia, hoje se observa que esses alunos possuem um potencial que ultrapassa os limites até então definidos. Atualmente, dispõese de especialidades que intervêm junto a esses alunos no desenvolvimento de suas potencialidades, prevenindo deformidades e outras possíveis deficiências que possam surgir secundariamente à PC

O computador e os recursos disponíveis, como os Ambientes Digitais (ADs), podem ser vistos como um salto de qualidade na vida de alunos com PC. Por meio de diversas adaptações possíveis, podem tornar-se importantes agentes facilitadores da aprendizagem e do desenvolvimento, além de instrumentos imprescindíveis para a comunicação, assumindo assim o papel de fundamentais promotores da inclusão social desses indivíduos. Com base no que foi exposto, esta pesquisa teve como proposta 
básica explorar recursos tecnológicos para observar o desenvolvimento, com criancas com PC, de processos de comunicação, através da interação em ambientes digitais.

\section{Questões de Investigação}

O objetivo geral deste trabalho foi observar e avaliar o processo de interação e de produção/construção da comunicação escrita de sujeitos com PC, com maior e menor experiência no uso de computadores, utilizando ADs, através da exploração de suas ferramentas nas dimensões on-line e off-line. Alem do mais, observar os erros ortográficos nas produções textuais dos alunos e analisar possíveis mudanças encontradas no desenvolvimento da comunicação escrita para responder a seguinte questão de pesquisa: Ambientes Digitais favorecem o processo de interação e construção da comunicação escrita em sujeitos com Paralisia Cerebral?

\section{Material e Método}

O presente estudo consistiu em uma pesquisa de caráter qualitativo, envolvendo o estudo de multicasos.

A coleta de dados foi realizada com observação direta baseada nas ferramentas do AD Eduquito e de uma rede social, e nos processos de desenvolvimento da comunicação escrita. Foram realizados registros descritivos das interações dos sujeitos, no contexto dos ADs. Após o uso dos ambientes, foram descritos os aspectos fonoaudiológicos e os relacionados ao processo de interação e comunicação oral e escrita, bem como a análise dos erros ortográficos encontrados. Os erros ortográficos analisados foram referidos por Zorzi (1998) e descritos em 11 categorias.

Para este estudo foram selecionados 9 alunos que estavam em atendimento especializado no Centro de Reabilitação Educandário São João Batista. Os alunos possuíam idade entre 9 e 18 anos, 5 alunos do gênero masculino e 4 do gênero feminino.

Todos os alunos estudavam em escolas de ensino regular e estavam alfabetizados. As séries variavam desde o $2^{\circ}$ ano do ensino fundamental até o $1^{\circ}$ ano do ensino médio. Os alunos inseridos neste estudo possuíam diagnóstico clínico de PC sem doenças associadas. Não foi levada em consideração neste estudo a etiologia da doença. O tempo de duração da coleta de dados foi de 13 meses.

Os procedimentos desta pesquisa constituíram-se das seguintes etapas: Inicialmente os sujeitos foram divididos em dois grupos, considerando sua experiência prévia à computadores, ou a falta dela. No chamado GRUPO 1 estavam os 5 alunos que possuíam maior experiência no meio digital. O GRUPO 2, foi composto por 4 alunos sem experiencia prévia ou falta de manuseio do computador. Segue-se com a apresentação dos ADAs que seriam trabalhados pelos alunos, a criação do e-mail para os que não possuíam conta de correio eletrônico e o cadastro de todos no AD Eduquito e na Rede Social. A partir disso, foi feito o acompanhamento e registro de observações do processo de interação e comunicação escrita nos dois grupos nos ambientes. Todos os alunos foram solicitados a construir textos a partir de temas sugeridos, o que resultou em duas produções textuais, realizadas em dias distintos. Os alunos construíram um texto coletivo, a partir de várias produções textuais próprias.

A participação dos sujeitos no estudo foi realizada de acordo com a resolução 196/96 do 
Conselho Nacional de Saúde (aspectos éticos de pesquisa em seres humanos), através da assinatura do Termo de Consentimento Livre Esclarecido, pelo responsável do aluno incluído na pesquisa.

\section{Recursos de ADAs}

\subsection{Eduquito}

O AD escolhido para este estudo foi o Eduquito. De acordo com Santarosa, Conforto e Basso (2012), o Eduquito teve sua elaboração fundamentada na abordagem sociointeracionista proposta por Vygotsky, o qual investiga como a interação social promove o desenvolvimento de Funções Psicológicas Superiores no desenvolvimento da vida de um indivíduo. O AD Eduquito permite o desenvolvimento de atividades que motivam o processo de crescimento individual e coletivo. Por esta razão, escolheu-se utilizar este $\mathrm{AD}$ inclusivo, que tinha o propósito de utilizar ferramentas que permitam a troca de conhecimentos através da mediação e da interação social.

\subsection{Rede Social}

A escolha de uma rede social deu-se por sua grande aceitação dentre o público-alvo da pesquisa. Além disso, foram consideradas questões como: (1) a familiaridade dos sujeitos com a lógica da ferramenta, bem como, sua facilitada apropriação; (2) a possibilidade de acesso irrestrito ao seu conteúdo e (3) por proporcionar interações interpessoais que valorizam a autonomia do sujeito. Com o estabelecimento da Web 2.0, conceitos como participação, interação, comunicação e partilha foram ressignificados ao serem projetados como possibilidades para a utilização de recursos tecnológicos. A web, como plataforma, passou a impulsionar a construção de diferentes ferramentas colaborativas, observando o usuário não mais como um mero receptor de informações, mas sim como alguém que participa, atua, contribui e produz conteúdos.

Conforme Tanja e Bosch (2009), sites de redes sociais têm se tornado cada vez mais populares com o surgimento da Web 2.0, a chamada segunda geração de comunidades baseadas na web, com o aumento da colaboração e compartilhamento entre usuários por meio de aplicativos como wikis, blogs e podcasts, feeds RSS, etc. Sites como o MySpace.com, Friendster e, mais recentemente, Facebook.com têm experimentado crescente popularidade, principalmente entre os jovens que usam essas novas tecnologias para criar comunidades de prática instantâneas.

\section{Discussão dos Resultados}

A análise dos dados foi realizada com base no emprego das ferramentas disponíveis no AD Eduquito, na rede social, nas narrativas do Quadro Branco (QB) e nos processos de desenvolvimento da comunicação oral e escrita. Para a presente pesquisa, cada aluno criou um codinome a fim de que, assim, tivesse sua identidade preservada. Esse recurso de identificação foi usado quando da elaboração do Livro Virtual (LV), desenvolvido através da ferramenta acessível QB. O estudo das informações levantadas foi dividido em dois momentos: análise individual e análise do grupo. Neles, empregaram-se tabelas para facilitar a visualização, sem qualquer caráter classificatório ou quantitativo, dos indicadores levantados, bem como as alterações encontradas na produção textual dos alunos. Dessa forma, foi possível calcular o percentual de erros ortográficos, por erro, 
CBIE-LACLO 2015

Anais dos Workshops do IV Congresso Brasileiro de Informática na Educação (CBIE 2015)

considerando o tipo de falta cometida por tempo e também por ambiente onde foi constatado o fato.

A primeira atividade envolvendo a produção textual participativa teve como retorno um total de 24 narrativas. A segunda, 20. Na última fase da coleta de dados, um novo grupo foi instituído dentro da rede social, nomeado de CLUBE DO LIVRO. O objetivo nessa etapa, sugerido pelos alunos, foi a elaboração do LV, com uso da ferramenta acessível $\mathrm{QB}$, disponível no Eduquito. A partir de outras narrativas, as crianças elaboraram uma história com super-heróis inventados por elas. O LV foi composto integralmente pelo grupo, e as narrativas resultantes durante todo o processo de coleta de dados, mantidas fielmente, sem mudanças ou adaptações. As imagens inseridas no ambiente pela mediadora foram desenhadas pelos próprios criadores, utilizando o programa Paint.

Como referido anteriormente, os sujeitos da pesquisa foram divididos em dois grupos, considerando sua experiência prévia computadores, ou a falta dela. No chamado GRUPO 1 estavam os GP, FP, BL, SM e SC, com melhor desempenho em relação aos demais participantes, possivelmente por possuírem maior experiência no meio digital. $\mathrm{O}$ GRUPO 2, composto por MV, SG, AQ e EK demonstrou mais dificuldade, talvez por falta de destreza prévia ou falta de manuseio do computador. Cada elemento criou e desenvolveu sozinho sua parte na história, elaborando de dois a seis fragmentos narrativos, até a finalização integral do livro.

Nesse processo, os participantes deixaram claro que suas contribuições não precisavam ser definitivas na produção dos colegas, podendo ser alteradas caso os autores originais não se sentissem confortáveis com o conteúdo. Tal comportamento é indicativo claro de que, apesar de tratar-se de uma produção coletiva, os novos autores não se sentiam plenamente autorizados a influenciarem nos rumos do material elaborado. O conceito de autoria ainda pareceu estar associado ao criador do texto, representativo do papel de proprietário do material, não sendo identificado um maior deslocamento do foco na autoria para o foco no conteúdo, anteriormente destacado por Primo e Recuero (2003), e reforçado por Haetinger et. al. (2005). A Tabela 1 apresenta dados referentes ao número de fragmentos narrativos produzidos pelos alunos dos dois grupos, dentro dos ADs.

Tabela 1 - Número de narrativas dos alunos divididos em grupos, dentro dos ambientes digitais

\begin{tabular}{|c|c|c|c|c|}
\hline \multicolumn{2}{|c|}{$\mathbf{N}^{\circ}$ de narrativas } & REDE SOCIAL & QB & TOTAL \\
\hline \multirow{5}{*}{$\begin{array}{l}\overrightarrow{0} \\
\stackrel{0}{0}\end{array}$} & GP & 2 & 6 & 8 \\
\hline & FP & 14 & 6 & 20 \\
\hline & SM & 5 & 3 & 8 \\
\hline & $\mathrm{SC}$ & 8 & 2 & 10 \\
\hline & $\mathrm{BL}$ & 4 & 2 & 6 \\
\hline \multicolumn{2}{|c|}{ TOTAL Gl } & $33(76,7 \%)$ & $19(65,5 \%)$ & $52(72, \%)$ \\
\hline \multirow{4}{*}{$\stackrel{\wp}{\underset{\sigma}{\sigma}} \mathrm{N}$} & MV & 2 & 3 & 5 \\
\hline & SG & 4 & 2 & 6 \\
\hline & $\mathrm{AQ}$ & 2 & 3 & 5 \\
\hline & EK & 2 & 2 & 4 \\
\hline \multicolumn{2}{|c|}{ TOTAL G2 } & $10(23.2 \%)$ & $10(34.4 \%)$ & $20(27,7 \%)$ \\
\hline \multicolumn{2}{|c|}{ TOTAL GERAL } & $43(59,7 \%)$ & $29(40,3 \%)$ & $72(100 \%)$ \\
\hline
\end{tabular}


Verificou-se que o grupo de alunos com maior experiência apresentou sempre mais que o dobro de produções escritas, se comparado ao de menor experiência. Entretanto, no QB, os alunos do GRUPO 2 evidenciaram proporcionalmente uma menor diferença em relação ao outro grupo. Esta diminuição da diferença pode ser relacionada ao fato de o QB ter sido utilizado no final do estudo, possibilitando aos alunos do GRUPO 2 um tempo maior para que se apropriassem das novas ferramentas introduzidas na pesquisa e, desta forma, serem capazes de revelar uma evolução no que afeta à produção de suas narrativas.

Foram identificados e analisados os erros produzidos individualmente pelos sujeitos da pesquisa a partir do material de escrita coletado dentro dos ambientes estudados. Os dados revelaram, em relação ao grande grupo, 348 alterações ortográficas em 4.371 palavras examinadas. Tal quantidade, somada à diversidade de tipos de alterações encontradas, causou, de imediato, dificuldades quanto a critérios de classificação das mesmas. Dúvidas de como interpretar ou considerar tais erros foram muito grandes e acabaram por motivar a busca de modos de classificação que já tivessem sido empregados e que pudessem auxiliar na pesquisa. Desta forma, acabou-se por utilizar a classificação proposta por Zorzi (1998), onde a partir de outros estudos, foi desenvolvido um quadro classificatório composto de 10 categorias ou tipos de alterações ortográficas que foram mais comumente encontradas na escrita das crianças em geral. Nesta classificação, Zorzi (1998) criou mais uma, para dar conta de certas idiossincrasias, ou seja, de certos modos particulares e pouco frequentes de escrever palavras que eram encontrados em uma ou outra criança, e que não poderiam ser considerados como dificuldades comuns à maioria dos sujeitos. A partir desses resultados, os dados foram agrupados de acordo com as etapas evolutivas da pesquisa: inicial (entre 1 e 6 meses) e final (entre 7 e 12 meses).

A Figura 1 apresenta o percentual de erros ortográficos por aluno, em relação ao número de palavras analisadas individualmente durante os dois momentos da pesquisa.

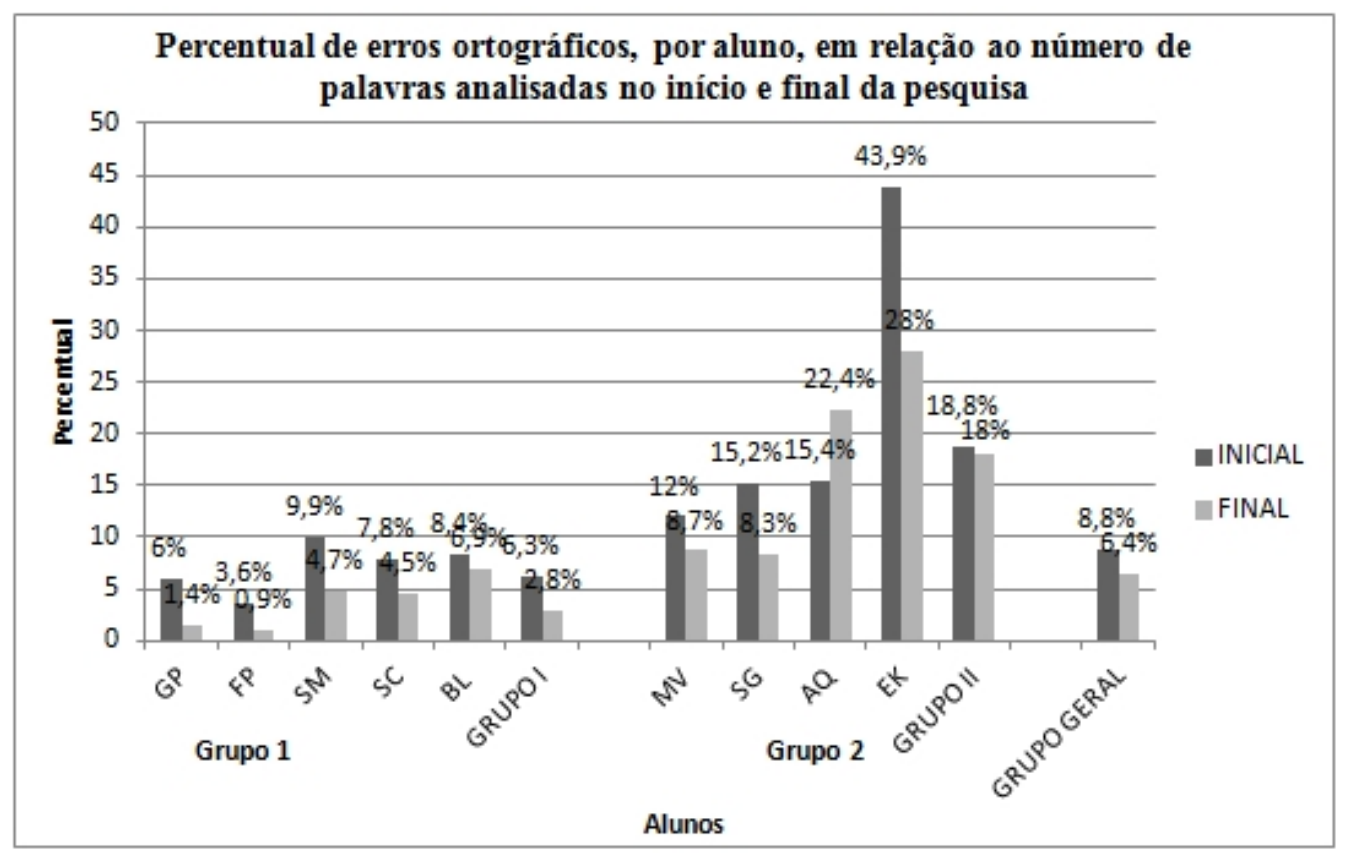




\section{Figura 1 - Percentual de erros ortográficos, por aluno, em relação ao número de palavras analisadas no início e final da pesquisa.}

É possível observar que 8 alunos apresentaram, na etapa final, menor percentual de erros em comparação ao início da pesquisa, exceto AQ, que obteve uma queda em seu rendimento durante o desenvolvimento do estudo. O GRUPO 1, equiparado ao outro grupo, teve um percentual menor de erros. NO GRUPO 1, GP alcançou $6 \%$ no começo e diminuiu esse total para $1,4 \%$ de erros no encerramento da análise. Isso aconteceu com todos os alunos desse grupo, sendo que FP iniciou com 3,6\% e finalizou com $0,9 \%$ de erros. SM passou de 9,9\% para 4,7\%. SC, com 7,8\% inicialmente, terminou com $4,5 \%$ e, por fim, BL, com $8,8 \%$, reduziu seu percentual para $6,9 \%$, sendo o pesquisado com menor redução na taxa de erros em seu grupo. O GRUPO 2 teve o seguinte perfil evolutivo no que concerne ao percentual de erros: MV, inicialmente com $12 \%$, diminuiu esse índice para 8,7\%; SG, com 15,2\% no começo, diminuiu para 8,3\%; EK, estudante que apresentou o maior percentual durante todo o estudo, de $43 \%$ na primeira fase, baixou esse valor para $28 \%$ de erros. Por fim, AQ, única criança com aumento no número de erros durante a investigação, passou de $15,4 \%$ a $22,4 \%$. Face a esta última situação apresentada, relativa à curva negativa de desempenho de $\mathrm{AQ}$, busco-se compreender o que houve no decorrer do processo que pudesse contribuir para esse resultado isolado. Foi verificado em seu histórico de atendimento se havia alguma evidência ou informação que explicasse de alguma forma um comportamento tão significativo concernente ao número de erros ortográficos. AQ não possuía computador com acesso à Internet em casa e só utilizava os ambientes trabalhados durante o tempo em que permanecia na pesquisa, ou em alguma atividade de informática oferecida pela escola. Apesar de demonstrar interesse pelas atividades, a família da criança não se interessava em auxiliá-la ou incentivar o uso da informática como apoio à sua deficiência. Após o término da investigação, AQ foi suspensa dos atendimentos na instituição por falta e por não adesão à terapia. Acredita-se que tal situação possa ser um dos fatores que incentivou esse desempenho de AQ.

De acordo com Vygostky (2011), a família deve compreender a criança como um ser em formação, que busca, por meio das experiências interpessoais, construir seu aprendizado. A família pode influenciar na aprendizagem escolar da criança na medida em que lhe oferece as primeiras instruções sobre regras morais e sociais. Nesse estudo, a família de AQ não só pode ter interferido em seu rendimento, no tocante à linguagem, como acabou prejudicando o andamento de sua terapia, no momento em que decidiu abandonar as atividades realizadas na instituição.

A diferença do percentual total de erros ortográficos verificados ao longo da pesquisa, respectiva à toda a pesquisa e à integralidade de seus participantes, acha-se exposta na Figura 2. 
CBIE-LACLO 2015

Anais dos Workshops do IV Congresso Brasileiro de Informática na Educação (CBIE 2015)

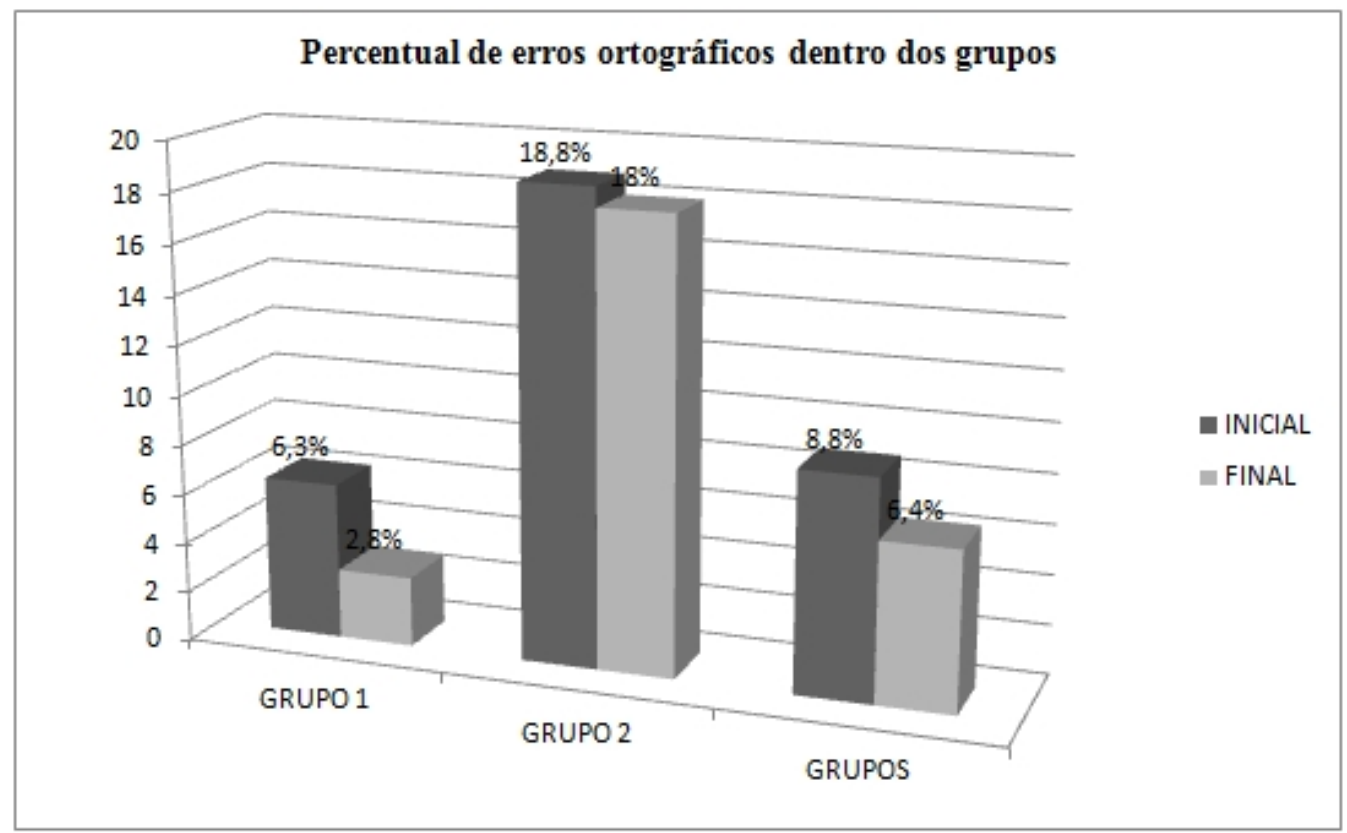

Figura 2 - Percentual de erros ortográficos dentro dos grupos.

O GRUPO 1 apresentou 6,3\% no primeiro momento e, no encerramento, caiu para $2,8 \%$. Por outro lado, o GRUPO 2, com um percentual inicial bem maior, $18,8 \%$, concluiu o estudo com 18\%, o que ainda representa uma quantidade considerável. Entretanto, pese a esse resultado, é preciso que se registre que o GRUPO 1 sempre apresentou melhor evolução da linguagem escrita quando comparado ao GRUPO 2 cuja melhora não representa alterações significativas em termos de mudança de comportamento na escrita. No que afeta aos resultados de todos os sujeitos envolvidos, verifica-se que começaram o processo com $8,8 \%$ de incidência de erros, reduzindo o resultado para $6,4 \%$.

$\mathrm{O}$ ato de apropriar-se das tecnologias digitais em virtude da inclusão sociodigital, bem como do favorecimento da comunicação por indivíduos com deficiência, traz à tona estudos que comprovam os benefícios da utilização das Tecnologias Assistivas como recurso no processo de construção de conhecimentos. Em suma, o grupo, em geral, no momento inicial da apresentação das novas ferramentas, necessitou de uma quantidade significativa de suporte. Gradativamente, essa quantidade de auxílio foi diminuindo, o que denota a progressiva autonomia dos sujeitos no transcorrer do processo interativo. Tais mudanças são evidências de maior apropriação/aprendizagem alcançadas pelos sujeitos.

Em um estudo realizado por Tanja e Bosch (2009), na Cidade do Cabo, onde o objetivo foi verificar a usabilidade da rede social Facebook para o ensino e aprendizagem, os autores argumentam que os alunos se valiam do ambiente para replicar na rede social o que acontecia em sala de aula, assumindo, assim, a condição de amigos "on-line" dos colegas da universidade. Esse mesmo processo de interação com o grupo geral foi verificado na presente investigação. Os estudantes, quando do início da pesquisa, conheciam-se superficialmente dentro da Instituição. Após o início deste estudo, os estudantes passaram a ter uma convivência mais frequente em um espaço colaborativo 
de ensino, estabelecendo vínculos de amizade também fora do contexto virtual.

\section{Conclusões}

Os resultados deste trabalho mostraram um processo bem sucedido em relação à produção das narrativas. Os estudantes passaram a produzir mais narrativas após a utilização dos ADs. Além disso, percebeu-se que os textos possuíam menor número de erros ortográficos, possibilitando uma melhora significativa na inteligibilidade da escrita e no processo de comunicação. Inicialmente, buscou-se incentivar a produção textual dos alunos através do ambiente Eduquito, porém, com o decorrer da coleta de dados, sentiu-se a necessidade de incluir um novo recurso nesse processo. A proposta de utilização da rede social como um $\mathrm{AD}$ apresentou inúmeros desdobramentos, colocando-se como importante ferramenta para pesquisas futuras. A rede social é, de fato, um ambiente poderoso de comunicação que emula, de forma notável, numerosíssimas formas de interação entre os sujeitos. Foi possível concluir que, quanto mais inovador é o ambiente, maior interesse é despertado nos alunos. No presente estudo, pode-se constatar que os alunos, além de produzirem um número maior de narrativas, interagiram mais dentro deste ambiente virtual que nos demais entornos estudados. A rede social mostrou-se um atrativo que incluía os alunos e fazia parte da sua rotina habitual.

Pode-se constatar, também, que é evidente a ausência de uma tradição de trabalhos que apresentem as possíveis modificações na comunicação de alunos com PC, através do uso das Tecnologias de Informação e comunicação. De modo geral, apesar da dificuldade na comparação dos resultados deste trabalho com o de outros estudos realizados sobre o tema, devido a diferenças nas metodologias empregadas e na patologia associada ao aluno, é possível verificar que os erros ortográficos cometidos pelos sujeitos com PC não se diferenciam, em sua natureza, daqueles observados em indivíduos que não o possuem. Vale ressaltar que os estudos encontrados não analisam a escrita digitada, e sim a escrita através da grafia.

$\mathrm{O}$ estudo evidenciou ainda aspectos relacionados à tendência de melhora dentro dos grupos. Em todos os aspectos analisados, observou-se que, de uma forma constante, os grupos apresentaram a mesma tendência de melhora. O GRUPO 1 melhorou em todos os aspectos, da mesma forma que o GRUPO 2. Apesar de o GRUPO 1 demonstrar um percentual sempre maior de melhora, a tendência do GRUPO 2 era a mesma. Também constatou-se aspectos relacionados ao padrão da escrita. Alguns alunos empregavam palavras abreviadas neste estudo e constou-se que esta prática ocorreu dentro de todos os ambientes estudados. A forma que o aluno utilizava a sua linguagem refletia em sua escrita.

Concluiu-se que esta investigação despertou o interesse para novas e futuras pesquisas na área. Os resultados obtidos contém fundamentos que asseguram a importância de trazer novas conclusões acerca deste tema proposto. Como trabalhos futuros relacionados, aponta-se para a investigação acerca das demais ferramentas que o Eduquito oferece e a sua relação com a comunicação. Os resultados positivos observados na linguagem escrita mostraram que é sempre possível descobrir novas dimensões ao utilizarmos a Informática como um recurso na comunicação de sujeitos com deficiências. Vale ressaltar que as novas tecnologias, que estão disponíveis hoje em dia, não oferecem aos sujeitos um novo mundo, sem problemas, mas pode servir para auxiliar e facilitar a vida cotidiana. Nesta investigação pôde-se observar que os 
ambientes trabalhados contribuíram com o favorecimento da participação, da expressão, da interação e, principalmente, da comunicação escrita de crianças com deficiência, apontando positivamente para as tecnologias digitais como recursos de apoio ao desenvolvimento de crianças com PC e, valorizando, assim, cada segundo dedicado a esse projeto.

\section{Referências}

Beck, F. L. A informática na educação especial: interatividade e representações sociais. Cadernos de Educação, vol 28, pág 175 - 196, 2007.

Galvão Fiho, T. A.; Damasceno, L. L. Programa InfoEsp: Premio Reina Sofia 2007 de Rehabilitación y de Integración. In: Boletín del Real Patronato Sobre Discapacidad, Ministerio de Educación, Política Social y Deporte. Madri, Espanha. n. 63, p. 14-23. 2008.

Haetinger, M. G. O Universo Criativo da Criança na educação: coleção Criar. Vol. 03. Rio Grande do Sul, 2005.

Primo, A. F. T.; Recuero, R. C. "Hipertexto Cooperativo: Uma Análise da Escrita Coletiva a partir dos Blogs e da Wikipédia”, Revista da FAMECOS, n. 23, p. 54-63, Dez. 2003.

Rabello, S. O uso do computador no desempenho de atividades de leitura e escrita do escolar com deficiência visual. Dissertação de Mestrado apresentada a Pós Graduação da Faculdade de Ciências Médicas da Universidade Estadual de Campinas. Campinas, 2007.

Rocha, A. N. D. C.; Deliberato, D. Tecnologia assistiva para a criança com paralisia cerebral na escola: identificação das necessidades. Revista Brasileira de Educação Especial. V.18, n.1.2012.

Santarosa, L. M. C.; Conforto, D.; Basso, L. "O. Eduquito: ferramentas de autoria e de colaboração acessíveis na perspectiva da web 2.0", Revista Brasileira de Educação Especial. [online]. 2012, vol.18, n.3, pp. 449-468.

Tanja E Bosch. "Using online social networking for teaching and learning: Facebook use at the University of Cape Town", Communication: South African. Journal for Communication Theory and Research, 35:2, 185-200, 2009.

Vygotsky, L. S. A Formação Social da Mente: o desenvolvimento dos processo psicológicos superiores. $7^{a}$ edição. São Paulo: Martins Fontes, 2007.

Vygotsky, L. S.; A defectologia e o estudo do desenvolvimento e da educação da criança anormal. Educação e Pesquisa, São Paulo, v.37, n.4, p. 861-870, dez. 2011.

VYGOTSKY, L. S. Pensamento e Linguagem. São Paulo: Martins Fontes, $4^{\mathrm{a}}$ edição. 2011.

Zorzi, J. L. Aprender a escrever: a apropriação do sistema ortográfico. Porto Alegre: ArtMed; 1998. 